\title{
Gene therapy targeting hepatocellular carcinoma by a dual-regulated oncolytic adenovirus harboring the focal adhesion kinase shRNA
}

\author{
YANG GAO, YAYUN ZHU, XINYU HUANG, KAIXING AI, QI ZHENG and ZHOU YUAN
}

Department of General Surgery, Shanghai Jiao Tong University Affiliated Sixth People's Hospital, Shanghai 200233, P.R. China

Received March 28, 2015; Accepted May 11, 2015

DOI: 10.3892/ijo.2015.3047

\begin{abstract}
Cancer targeting gene-viro-therapy (CTGVT) approach has become a hotspot and a trend in the field of cancer biotherapy and oncolytic adenovirus is an ideal vector to carry the targeting genes. In this study, we used human telomerase reverse transcriptase (hTERT) promoter to control the adenovirus early region $1 \mathrm{a}(\mathrm{E} 1 \mathrm{~A})$ and the human $\alpha$-fetoprotein (AFP) promoter integrated with hypoxia response element (HRE) to control the adenovirus early region $1 \mathrm{~b}(\mathrm{E} 1 \mathrm{~B})$. Then the novel double-regulated adenovirus Ad-hTERT-HREAF (named SG505) was engineered. The short-hairpin RNA against focal adhesion kinase (FAK) was inserted into SG505 and thus forming Ad-hTERT-HREAF-shRNA (called SG505-siFAK). Then various oncolytic adenoviruses were examined to verify whether they could suppress liver cancer cells selectively and efficiently both in vitro and in vivo. Both replicative and replication-defective adenoviruses carrying FAK-shRNA significantly inhibited the expression of FAK in Hep3B and SMMC-7721 cell lines and efficiently suppressed the growth of liver cancer cell lines with minor effect to normal cells. Furthermore, the recombined oncolytic adenoviruses, SG505siFAK, SG505-EGFP and SG505 were able to selectively propagate in AFP-positive liver cancer cells in vitro and the SG505-siFAK efficiently suppressed the expression of FAK. SG505-siFAK showed the most potent tumor inhibition capability among the three recombined adenovirus with $\mathrm{IC}_{50}$ levels of $0.092 \pm 0.009$ and $0.424 \pm 0.414$ pfu/cell in the Hep3B and HepG2 cell line, respectively. Animal experiment further confirmed that SG505-siFAK achieved the most significant tumor inhibition of Hep3B liver cancer xenografted growth by intratumoral injection comparing to the intravenous injection among the three recombined viruses. Immunohistochemical results indicated that FAK expression was downregulated significantly in the tumors treated with SG505-siFAK. The
\end{abstract}

Correspondence to: Dr Zhou Yuan, Department of General Surgery, Shanghai Jiao Tong University Affiliated Sixth People's Hospital, 600 Yishan Road, Shanghai 200233, P.R. China

E-mail: zhouyuan669@163.com

Key words: cancer targeting gene-viro-therapy, oncolytic adenovirus, hepatocellular carcinoma, focal adhesion kinase, RNA interference dual-regulated oncolytic adenovirus SG505-siFAK was proven to inhibit the growth of liver cancer cells selectively and efficiently, therefore SG505-siFAK could be a potential agent for future clinical trials of hepatocellular carcinoma.

\section{Introduction}

Hepatocellular carcinoma (HCC) is one of the most frequently diagnosed cancers and is also one of the major causes of tumor-related deaths worldwide (1). With the improvement of the surgical techniques and the application of transarterial chemoembolization (TACE), the radiofrequency ablation (RFA), and liver transplantation, the overall survival and the prognosis have made great progress and the 5-year survival rate of the early diagnosed HCC with curative treatments ranges from 50 to $70 \%$, but the recurrence of early-stage HCC after resection occur in $\sim 20,50$ and $75 \%$ of patients at 1,3 and 5 years, respectively $(2,3)$. Therefore, the recurrence and the metastasis after resections are intractable problems for achieving total control in HCC treatment, while there are few drugs to resolve the crucial problem. At present, the only approved systematic therapy for the advanced-stage HCC patients is the multikinase tyrosine kinase inhibitor sorafenib which used alone improves the median overall survival by $\sim 3$ months $(4,5)$. Thus, it is urgent to pursue new agents to improve the prognosis of HCC.

Cancer targeting gene-viro-therapy (CTGVT) is a promising approach to conquer the malignant tumor as it is endowed with the ability to selectively infect and damage the tumor cells with minimum harm to the normal tissue (6). The new strategy takes advantage of gene therapy and virotherapy by utilizing the oncolytic adenovirus containing the anticancer gene, which produces more effective antitumor effects than either gene therapy or the viral therapy alone $(7,8)$. The adenovirus vectors are the most common used gene delivery system, especially the adenovirus serotype 5 (Wad5) due to its excellent characteristics. Adenovirus can replicate in both dividing and non-dividing cells and it hardly integrates into the host genome posing low risk of mutagenesis. The easy manipulation and the capability to produce high tilters of virus are favorable. Moreover, the adenovirus activates the humoral and cellular immune response which might activate immune system for the recognition of tumor antigens. The side effects of adenovirus therapy are mild and rare. So adenovirus is an ideal candidate 
vector for the CTGVT (9). The oncolytic adenovirus, also called conditionally replicating adenovirus, could theoretically selectively propagate in and lyse the tumor cells and the released progeny virus will evade the neighboring tumor cells and the virus replication will stop in the normal cells $(9,10)$. To achieve the targeting therapy of HCC and safety for the normal cells, a dual-regulated oncolytic vector by using liver cancer-specified promoters was then constructed.

Human telomerase reverse transcriptase (hTERT) is highly active in $>80 \%$ of human tumor cells but not in most normal cells and the hTERT promoter has been cloned by several scientists and was utilized to drive the exogenous gene expression $(11,12)$. The adenovirus early region 1a (E1A) plays a central role in the virus replication and cell cycle and the E1A promoter can be replaced by the hTERT promoter (13). However, hTERT is also expressed in the hematopoietic stem cells and generative cells, so the system has a potential detriment to the normal cells and will produce side effects in humans. To minimize the potentially adverse effects to normal cells, more delicate regulatory systems should be engineered. Human $\alpha$-fetoprotein (AFP) is re-expressed in $\sim 70 \%$ of the $\mathrm{HCC}$, so the AFP promoter is widely used to drive the adenovirus E1B gene as an excellent tool for HCC targeting therapy $(14,15)$. The system can be used to target to the AFP-positive HCC specially, but does not work in the low-AFP-generating cells or AFP-negative cells so we created a fused AFP promoter, HREAF, by connecting the hypoxia reactive element (HRE) enhancer with the AFP and the system is able to enhance the replication capability of oncolytic adenoviruses in both AFP-positive and AFP-negative liver cancer cells $(16,17)$. However, there exists a disadvantage in this system that it can also kill the hepatic stem cells which also express AFP, thus weakening the hepatic reserve and worsening the prognosis of the HCC patients. It has been reported that the HREAF promoter enhanced the translational strength and selectivity of the oncolytic virus to achieve HCC-specific and tumor environment-selective viral replication and tumor killing $(17,18)$. In order to achieve the hepatoma-restricted cytotoxicity and enhanced replication, we integrated the hTERT promoter and HREAF promoter into our oncolytic adenovirus where the hTERT promoter drove the E1A expression and the HREAF drove the E1B expression, then the Ad-hTERT-HREAF was constructed and we named it SG505.

Previous studies revealed that the focal adhesion kinase (FAK) expression was upregulated in HCC and the high expression was associated with a poor prognosis $(19,20)$. FAK besides contributing to the invasion and metastasis of the HCC, also proved to be an important mediator of cell adhesion, growth, proliferation, survival, angiogenesis and migration which were often disturbed in the cancer cells, so it was a promising therapeutic target for the HCC (21). Herein, we created the short-hairpin RNA against FAK and inserted the gene in the recombined oncolytic adenovirus to confirm the antitumor effect and the new system was Ad-hTERTHREAF-FAK-shRNA, or SG505-siFAK for short. We also created other recombined adenoviruses, namely, Ad-hTERTHREAF-EGFP-shRNA (SG505-EGFP), Ad-PPE3-siFAK, and Ad-DC311-siFAK. In this study, we explored the selective and efficient antitumor effect of the recombined oncolytic adenovirus to offer better treatments for HCC.

\section{Materials and methods}

Cell lines and culture conditions. HEK293 cells (embryonic kidney cell line containing the E1A region of serotype adenovirus 5) were purchased from Canadian Microbix Biosystem Inc. Hep3B and HepG2 (AFP-positive human liver cancer cell), SMMC-7721 (AFP-negative human liver cancer cell), L02 (human normal liver cell line), BJ (skin fibroblasts), PANC-1 (poorly differentiated pancreatic carcinoma cell line) and H460 (human large cell lung carcinoma cell line) were obtained from Cell Bank of Shanghai Institutes for Biological Sciences of the Chinese Academy of Sciences (Shanghai, China). Cells were cultured in DMEM or RPMI-1640 supplemented with $10 \%$ fetal bovine serum, $4 \mathrm{mmol} / \mathrm{l}$ glutamine, $50 \mathrm{U} / \mathrm{ml}$ penicillin and $50 \mu \mathrm{g} / \mathrm{ml}$ streptomycin under an atmosphere of $95 \%$ air and $5 \% \mathrm{CO}_{2}$.

Recombinant adenoviruses. Short hairpin RNA targeting FAK was constructed in our lab. The hybrid HREAP promoter and hTERT were generated referring to the previous studies $(16,22)$. Therefore, the shuttle plasmids Ad-DC311-siFAK, Ad-PPE3-siFAK and the dual-specific antitumor oncolytic adenovirus SG505, SG505-EGFP, SG505-siFAK were constructed. Briefly, shuttle plasmids were constructed to generate the recombinant. Packing and production of the recombinant adenoviruses were performed in the HEK-293 cells using Lipofectamine 2000 (Gibco BRL, Grand Island, NY, USA) according to the manufacturer's protocol. Viral plaques appeared 9-14 days after cotransfection and were sublimated three times. The recombinant adenoviruses were identified separately by PCR. The viral titers were determined by the tissue culture infectious dose $50\left(\mathrm{TCID}_{50}\right)$ assay in HEK293 cells.

Western blot analysis. Cells were infected with the recombinant adenoviruses at a MOI of 3 pfu/cell. The cells were trypsinized, harvested and resuspended in RIPA lysis buffer 3 days later. The protein concentration was confirmed by the avidin-biotin complex (ABC) technique as described by the manufacturer. Then, protein samples were separated by $10-15 \%$ SDS-polyacrylamide gel electrophoresis and transferred to polyvinylidene fluoride (PVDF) membranes. Membranes were blocked in 5\% bovine serum albumin (BSA) and incubated with primary antibodies at $4^{\circ} \mathrm{C}$ overnight and then were detected by the appropriate secondary antibodies marked with horseradish peroxidase at $37^{\circ} \mathrm{C}$ for $2 \mathrm{~h}$. Signals were visualized via the enhanced chemiluminescence (ECL) Western blotting substrate kit. Extracts of uninfected cells were used as the negative control and $\beta$-actin was used as the internal control.

MTT assay and BrdU incorporation assay. The MTT colorimetric assay was carried out to detect cell viability $(23,24)$. To assess the cytotoxic effect of the virus, cells on logarithmic phase were seeded onto 96 -well plates at $1 \times 10^{3}-2 \times 10^{3}$ cells per well and infected with oncolytic adenovirus. The viruses were diluted by serum-free culture solution. The cells were then infected with various concentrations (at MOI of 0.1, 0.2, 0.5, $1,2,5,10$ and $100 \mathrm{pfu} / \mathrm{cell}$ ) of recombinant adenovirus $24 \mathrm{~h}$ later. The cells without virus infection were used as controls 
and 4 duplications were set corresponding to a certain MOI value. The media was replaced by $100 \mu l$ phosphate-buffered saline (PBS) per well. The cells were treated with $5 \mu \mathrm{l}$ MTT $(5 \mathrm{mg} / \mathrm{ml})$ and incubating for $4 \mathrm{~h}$ at $37^{\circ} \mathrm{C}$ to allow MTT metabolization. Then the culture medium was removed and the crystals formed were dissolved in $150 \mu 1$ MTT lysate solution (70\% dimethylsulfoxide and $0.02 \mathrm{~mol} / \mathrm{l}$ hydrochloric acid) for $4 \mathrm{~h}$ at $37^{\circ} \mathrm{C}$. Cell viability was determined by measuring absorbance at $595 \mathrm{~nm}$, using a microplate reader. The controls at each day were set as $100 \%$ viability. The percentage of cell survival rate treated with the recombinant adenovirus was expressed using the following formula: [100\% x (absorbance value of experimental cells) / (absorbance value of control cells)]. All measurements were performed in triplicate. Bromodeoxyuridine (BrdU) incorporation was measured using BrdU Cell Proliferation Assay Chemicon cat. no. 2750. Transfected cells were incubated with BrdU for the last $12 \mathrm{~h}$ of the 72-h treatment with FAK siRNA and BrdU incorporation was assessed as described in the manufacturer's protocol. The concentration resulting in $50 \%$ of cell growth inhibition $\left(\mathrm{IC}_{50}\right)$ was calculated using SPSS version 17.0.

Real-time RT-PCR analysis. Real-time PCR was carried out on the Real-Time PCR system (Applied Biosystems) with the following conditions: $95^{\circ} \mathrm{C}, 15 \mathrm{sec}$ for 1 cycle; then $95^{\circ} \mathrm{C}$, $5 \mathrm{sec}$; and $60^{\circ} \mathrm{C}, 30 \mathrm{sec}$ for 45 cycles. The mRNA expression of FAK was measured on ABI 7,500 Real-Time PCR system with $\beta$-actin used as a control. Each experiment was repeated three times. RNA levels were calculated from the mean relative quantity $(\mathrm{RQ})\left(\mathrm{RQ}=2^{-\Delta \Delta \mathrm{C} t}\right)$.

Tumor xenograft experiment. Eighty female BALB/c nude mice (4-week-old) were purchased from the Shanghai Experimental Animal Center (Shanghai, China). To establish xenograft tumors, $5 \times 10^{6} \mathrm{Hep} 3 \mathrm{~B}$ cells in $500 \mu \mathrm{l}$ normal saline were subcutaneously injected into the right flank of each mouse. When the largest diameter of tumors reached $5 \mathrm{~mm}$, 40 mice were divided randomly into four groups (10 mice per group). PBS or $2 \times 10^{8} \mathrm{pfu}$ of Wad5, SG505, SG505-siFAK were administered to each mouse by intravenous injection every other day into the tumors five times. All injections were given every 2 days during the first week (days 3,5 and 7 after grouping) and once weekly for 2 more weeks (days 14 and 21 and so on after grouping). The remaining 40 nude mice received the treatments and measurements as described above by intratumoral injection. Tumor size was measured using calipers twice a week and calculated with a formula of [0.52 x (smallest diameter) $)^{2} \times$ (largest diameter)] (25), tumor inhibition rates was calculated using the formula (1 - tumor weight of experimental group/average tumor weight of control group) $\mathrm{x} 100 \%$. During the animal experiment, all animals were monitored daily and sacrificed at the end of the experiment. Ethics approval was granted by the Ethics Committee of the Affiliated Sixth People's Hospital of Shanghai Jiao Tong University.

Immunohistochemical analysis. Tumors were harvested and fixed in $4 \%$ paraformaldehyde, embedded in paraffin and cut into $4-\mu \mathrm{m}$ sections for immunohistochemical analysis after sacrifice. These sections were stained with monoclonal
anti-FAK antibodies at a 1:500 dilution. The slides were then washed with PBS and incubated with the avidin-biotin-peroxidase complex reagent. Then the differential expression of FAK in various tissues were studied. The criteria applied to evaluate the FAK staining intensity were described previously (19).

Statistical analysis. Statistical analysis was carried out by SPSS 17.0. All continuous data were presented as mean \pm standard deviation (SD). Categorical variables were compared by the $\chi^{2}$ test or Fisher's exact test. The independent sample t-test or ANOVA was used to compare the mean values of different groups. P-value $<0.05$ was considered statistically significant.

\section{Results}

Construction and characterization of the recombinant oncolytic adenovirus. SG505-siFAK was a dual-regulated oncolytic adenovirus with E1A driven by the hTERT promoter and E1B driven by the HREAF promoter and it was armed with the therapeutic gene siFAK. The SG505 was blank vector and SG505-EGFP was armed by the reporter gene enhanced green fluorescent protein (EGFP). Replicative Ad-PDC311siFAK virus and replication-defective Ad-PPE3-siFAK virus were initially introduced by the siFAK to confirm the function of RNA interference targeting to the FAK (Fig. 1A). The sequences of the inserted parts in all of the recombinant vectors were analyzed and proved to be correct.

It has been reported that the FAK was overexpressed in the HCC tumor but not in the normal tissue, so we constructed a targeting siFAK which will inhibit the FAK expression by the RAN interference technology $(19,20,26)$. The synthetic gene was then inserted into the replicative adenovirus Ad-PPE3 and replication-defective adenovirus AD-DC311. To evaluate FAK expression in tumor cells, we employed the real-time PCR to analyze the levels of the FAK mRNA in vitro. All of the samples were analyzed and the expression of $\beta$-actin mRNA transcripts were used as internal control. We found that the relative expression level of FAK mRNA in Hep3B cells infected by the Ad-PPE3-siFAK was significantly lower than that infected by the Ad-PPE3 $(0.137 \pm 0.015$ vs. $1.003 \pm 0.06 ; \mathrm{P}<0.01)$ and the relative expression level of FAK mRNA in Hep3B cells infected by the Ad-DC311-siFAK was also significantly lower than that infected by the Ad-DC311 $(0.357 \pm 0.021$ vs. $1.000 \pm 0.044 ; \mathrm{P}<0.01)$, so we can confirm that the FAK-siRNA has potential to be an effective therapeutic gene for HCC (Fig. 1C).

As FAK is a potential therapy targeting the tumor and knockdown of the FAK suppressed the growth of the HCC, as established herein, to evaluate the antitumor ability of the oncolytic adenovirus expressing the FAK shRNA in vitro, we measured the cell viability by MTT assay. We found that the liver cancer cell lines (Hep3B and SMCC7721) were sensitive to the Ad-PPE3 and Ad-DC311 infection, whereas the normal cell lines (BJ and L02) showed much lower sensitivity, demonstrating safety of the vectors expressing siFAK to the normal cells (Fig. 1D). Similar results were also confirmed by BrdU incorporation assay (Fig. 1E). Collectively, these data indicated that RNA interference against FAK functioned as a suppressive factor of FAK. The primary studies paved the way for further investigations for HCC treatment. 

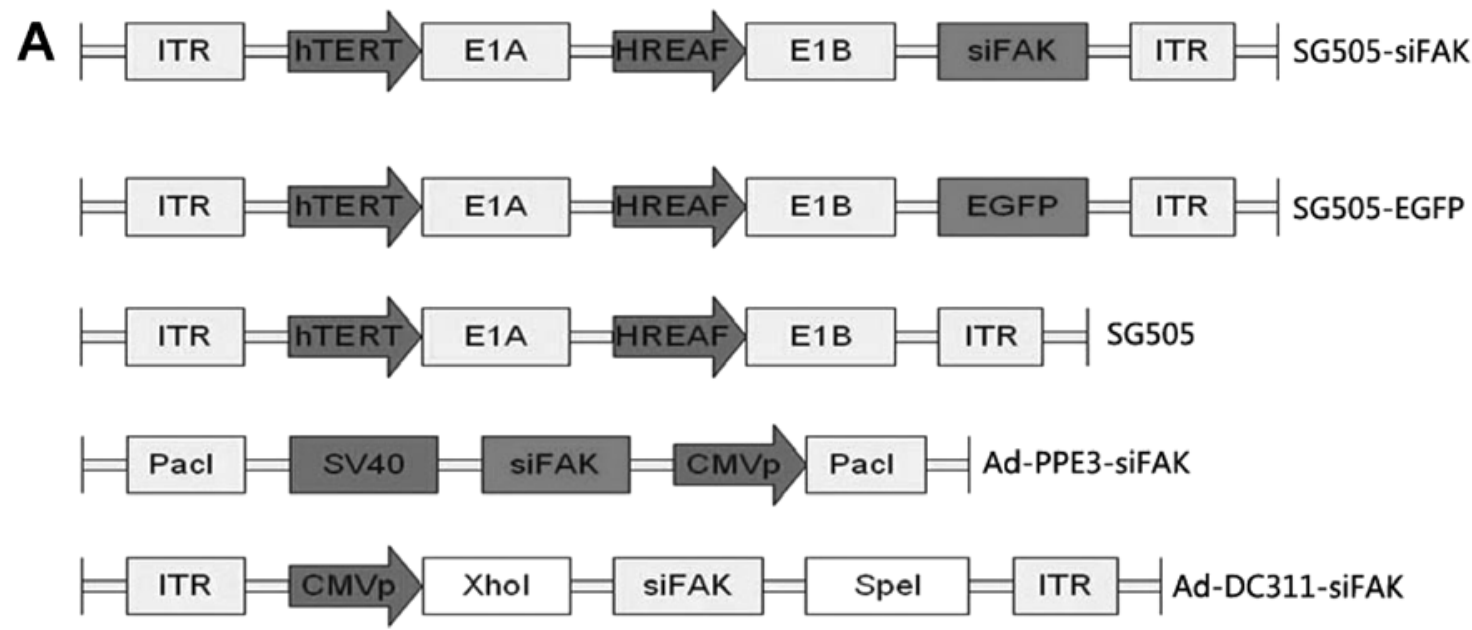

B

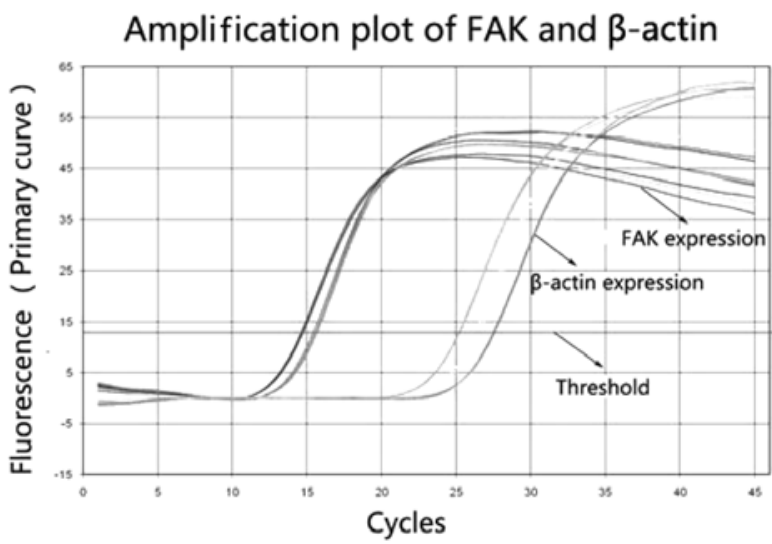

C

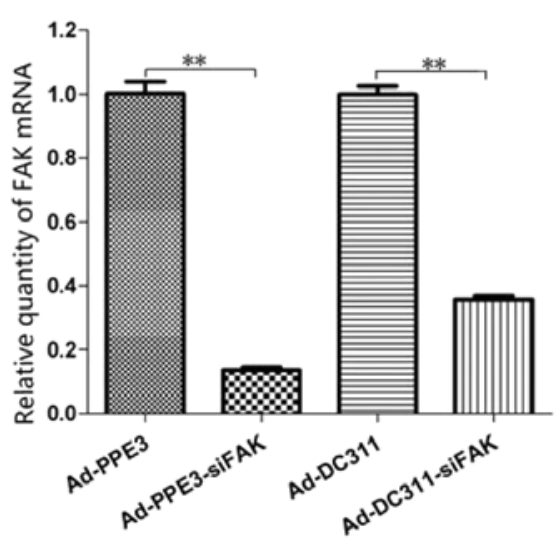

Figure 1. The structure of the recombined oncolytic adenovirus and the function of the FAK-shRNA. (A) Schematic diagram of recombinant adenoviruses. Schematic diagram of organization depict the elements in the recombinant adenovirus (SG505-siFAK, SG505-EGFP and SG505); the hTERT promoter drove the E1A expression and the hybrid HREAF promoter drove the E1B expression. The Ad-PPE3-siFAK and Ad-DC311-siFAK contained the siFAK elements. (B) Amplification plot based on quantitative real-time PCR of HepG2 FAK expression and $\beta$-actin expression. The siFAK was transfected to Ad-PPE3 and Ad-DC311 separately. (C) Quantification of the FAK mRNA transcript level in the Hep3B by four different viruses. The relative levels of the FAK mRNA were examined by the RT-PCR and reflected the relative expression compared with control sample, the results indicated that short-hairpin RNA against FAK could efficiently inhibit the FAK expression at the transcriptional level. All results were normalized and were representatives of triplicate readings from each treatment $\left({ }^{* *} \mathrm{P}<0.01\right)$.

Selective replicative ability of the recombined oncolytic adenovirus to AFP-positive liver cancer cells. To confirm the virus infective ability, the virus yields of different viruses were assayed using the standard tissue culture infectious dose $50\left(\mathrm{TCID}_{50}\right)$ assay. Virus replication rates were determined at $96 \mathrm{~h}$ after the cells were infected with Wad5, SG505, SG505-EGFP and SG505-siFAK separately at a MOI of $5 \mathrm{pfu} /$ cell. Previous studies have already assayed the AFP secretion ability of various liver cell line, which indicated that Hep3B and HepG2 cell lines secreted AFP at level of $1,174 \pm 17.33$ and $38.20 \pm 1.29 \mathrm{ng} / \mathrm{ml}$ and the secretion of AFP by L02 and SMMC-7721 was undetectable (7). The recombined oncolytic adenoviruses showed more potent replicative abilities in the Hep3B and HepG2 cell lines with the replication increasing by $\sim 10^{8}$-fold, compared to the AFP-negative cell lines, including the SMMC-7721, L02, BJ, PANC-1 and H460 cell lines $(\mathrm{P}<0.05)$ (Fig. 2A). Notably, Wad5 displayed the strongest replicative ability among various kinds of viruses in the cell lines. Although the recombined adenoviruses were slightly low in virus yield compared to Wad5, it was potent enough to drive the expression of the exogenous gene. The FAK expres- sion was significantly downregulated in the Hep3B and HepG2 cell lines infected by the SG505-siFAK (Fig. 2B). Therefore, it also confirmed that SG505 was a promising vector to deliver the siFAK which could effectively suppress the FAK expression. In addition, the virus tilters of SG505, SG505-EGFP and SG505-siFAK in the normal BJ and L02 cell were remarkably weaker than that of Wad5, which indicated less damage to the normal cells. The results demonstrated that recombined adenoviruses had significantly higher replication rates in the AFP-positive liver cancer Hep3B, and HepG2 cells and the safety concerning the recombined adenoviruses was remarkably balanced.

To further investigate the selective invasion of the dualregulated oncolytic adenovirus, we applied western blot analysis to analyze the E1A and E1B expression in different cell lines infected by various viruses. E1A and E1B gene expression in the infected cells provided an independent verification of virus replication because they were essential for the virus replication (27-29). In BJ cells, it was clear that detectable levels of E1A and E1B were only produced by the Wad5-infected cells while they were not detected in the other 
D

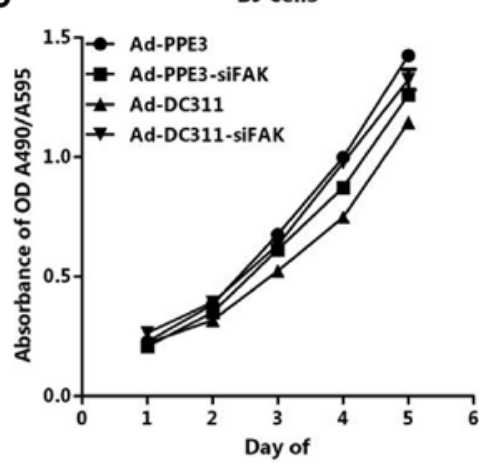

Hep3B cells

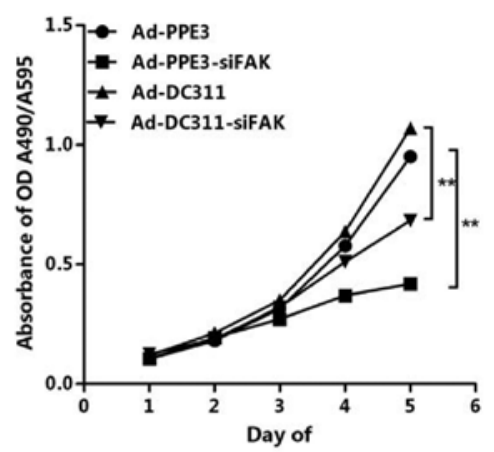

L02 cells

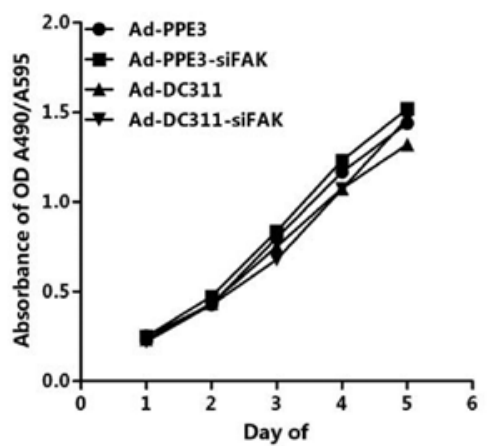

SMMC-7721 cells

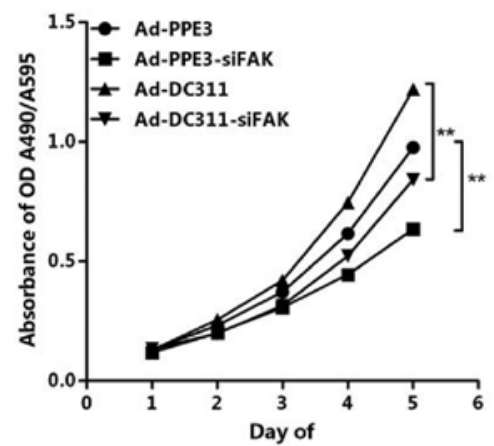

E

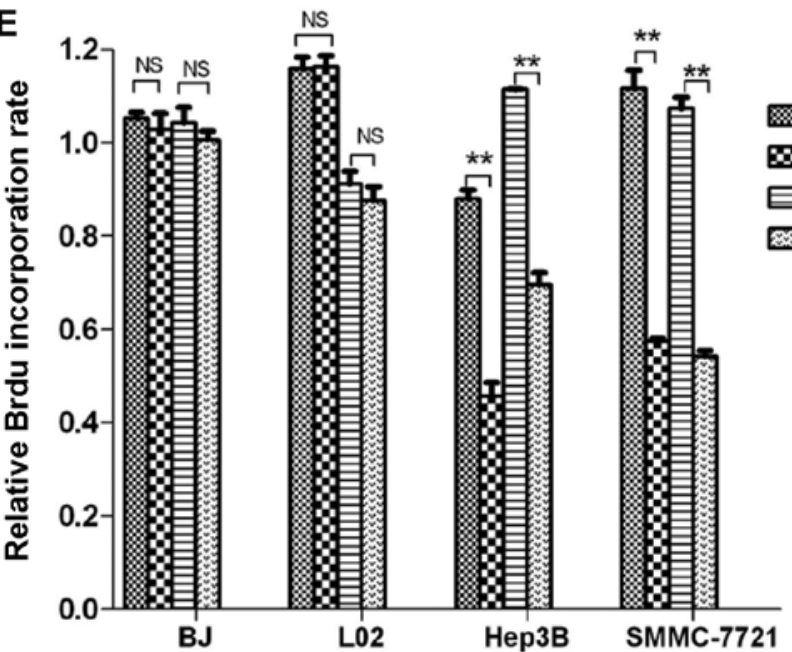

Figure 1. Continued. (D) The siFAK specially inhibited the growth of tumor cells. Silencing of FAK impaired the cell viability of Hep3B and SMMC-7721 cells. After transfection with Ad-PPE3, Ad-PPE3-siFAK, Ad-DC311, Ad-DC311-siFAK for 48 h, BJ, L02, Hep3B and SMMC-7721 cells were seeded into 96-well plates (2,000/well) and incubated for the indicated times. Measurement of cell viability of normal cells (BJ and L02) and liver cancer cells (Hep3B and SMMC-7721) every day after injection with different recombined adenovirus at a MOI of $1 \mathrm{pfu} / \mathrm{cell}$ by MTT assay. Points indicated the mean value (n=3); bars indicated $\mathrm{SD},{ }^{* *} \mathrm{P}<0.01$. (E) BrdU incorporation assay at $72 \mathrm{~h}$. The siFAK had no obvious effect on the growth rate of normal BJ cells and L02 cells. However, the growth rates of liver cancer line Hep3B infected with Ad-PPE3-siFAK and Ad-DC311-siFAK were significantly inhibited compared to the ones infected with the Ad-PPE3 and Ad-DC311 ( $0.457 \pm 0.051$ vs. $0.880 \pm 0.032, \mathrm{P}<0.01$ and $0.695 \pm 0.045$ vs. $1.114 \pm 0.001, \mathrm{P}<0.01$, respectively). Ad-PPE3-siFAK and Ad-DC311-siFAK could also decrease the SMMC-7721 growth rate compared to the Ad-PPE3 and Ad-DC311 $(0.575 \pm 0.011$ vs. $1.117 \pm 0.007, \mathrm{P}<0.01$ and $0.542 \pm 0.020$ vs. $1.073 \pm 0.042, \mathrm{P}<0.01$, respectively). The points indicated the mean value $(\mathrm{n}=3)$; bars indicated SD. ${ }^{* *} \mathrm{P}<0.01$.

four oncolytic adenoviruses (Fig. 3A). Besides, in the normal liver cell line (L02), the E1A and E1B were weakly expressed in the cells infected by SG505-siFAK, SG505 and SG505EGFP compared to Wad5, which confirmed the safety to the normal viable cells (Fig 3A). The expression of E1A and E1B in HepG2 and Hep3B infected by the oncolytic adenovirus was comparable to the ones by Wad5, which implied that the oncolytic adenoviruses produced large amounts of progeny viruses (Fig. 4B).
The cytotoxic effects of dual-regulated oncolytic adenovirus in AFP-positive liver cancer cell lines. Next, we investigated the antitumor effect of the viruses on cell viability. The AFP-positive liver cancer cell lines (Hep3B and HepG2), AFP-negative liver cancer cell line (SMMC-7721), human normal liver cell line (L02), PANC-1 and H460 were infected with Wad5, SG505, SG505-siFAK and SG505-EGFP at consistent MOIs ranging from 0.1 to $100 \mathrm{pfu} / \mathrm{cell}$. Overall, the cell viability declined gradually with the increasing 


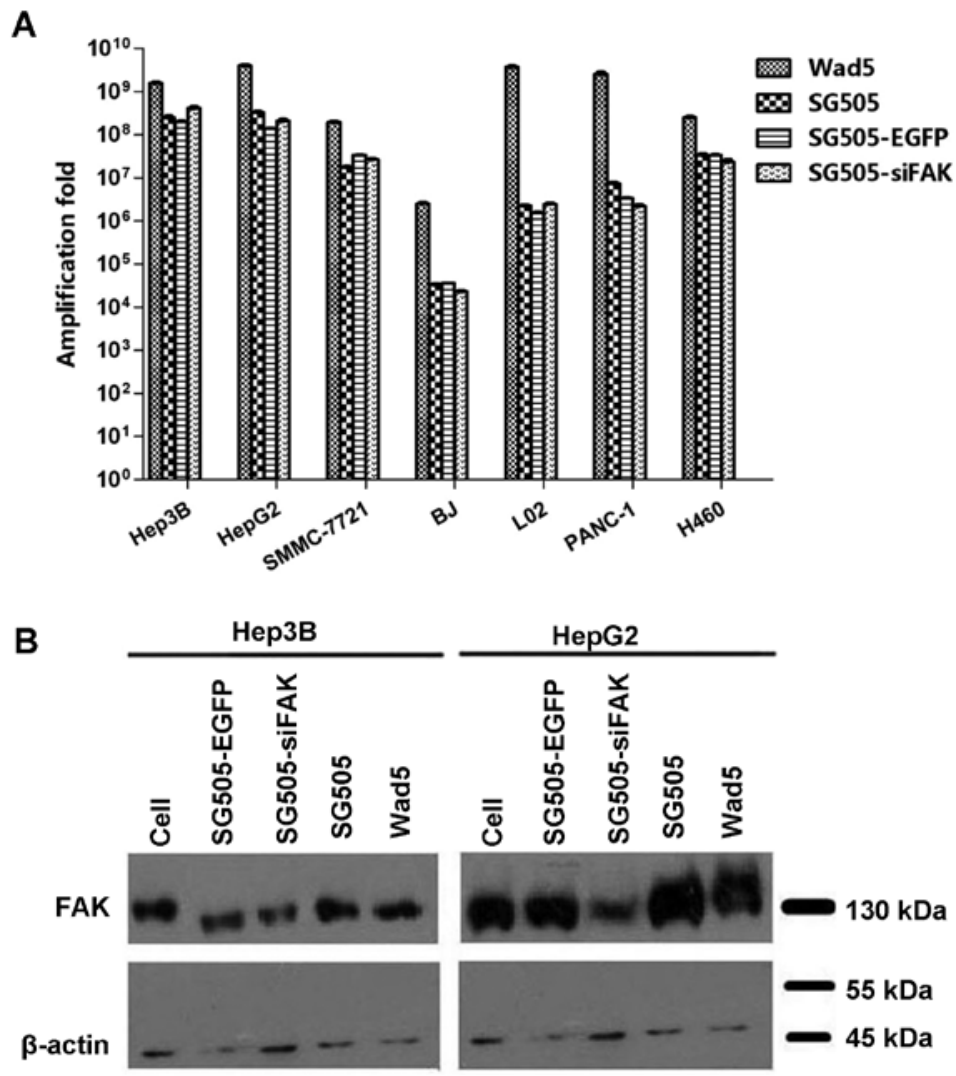

Figure 2. The replication ability of the oncolytic adenoviruses in various cell lines. (A) Replicative ability of Wad5, SG505, SG505-EGFP and SG505-siFAK in various cell lines are shown. Cells were infected with $5 \times 10^{5} \mathrm{pfu}$ of the indicated viruses (MOI=5) and viruses were harvested $96 \mathrm{~h}$ later, virus tilters were qualified by the $\mathrm{TCID}_{50}$ assay. Amplification fold (yield virus/input virus) is shown. The bars represent the mean amplification fold of each adenovirus infecting different cells; the data are given as the mean \pm SD of triplicate samples. (B) Analysis of FAK expression in the liver cancer cells. Western blotting was applied to analyze the FAK expression in AFP-positive liver cancer cell lines Hep3B and HepG2. $\beta$-actin expression was used as internal control.

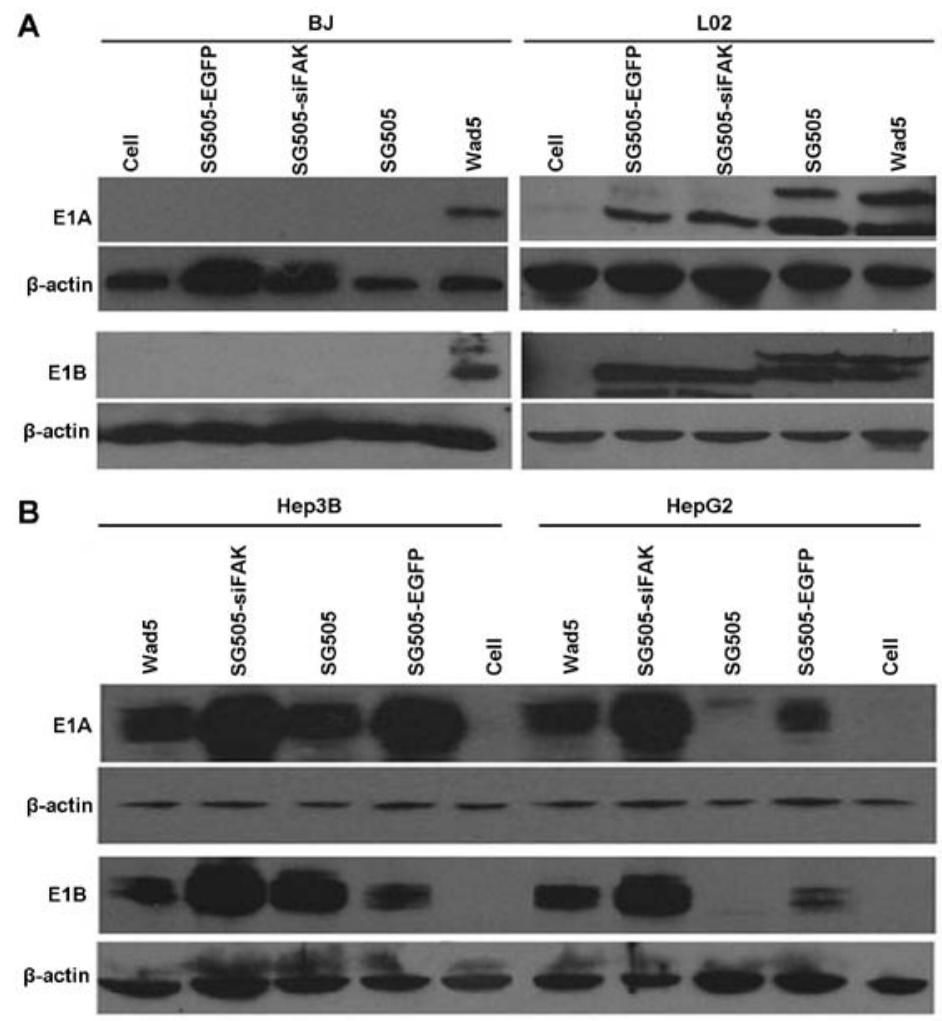

Figure 3. Western blot analysis of E1A and E1B gene expression in BJ, L02 cells (A) and Hep3B and HepG2 cells (B). Cells were infected by Wad5, SG505, SG505-siFAK and SG505-EGFP at a MOI of $3 \mathrm{pfu} / \mathrm{cell}$, and were harvested after 3 days, the lysates were analyzed by western blot analysis. The $\beta$-actin expression served as a loading control. 


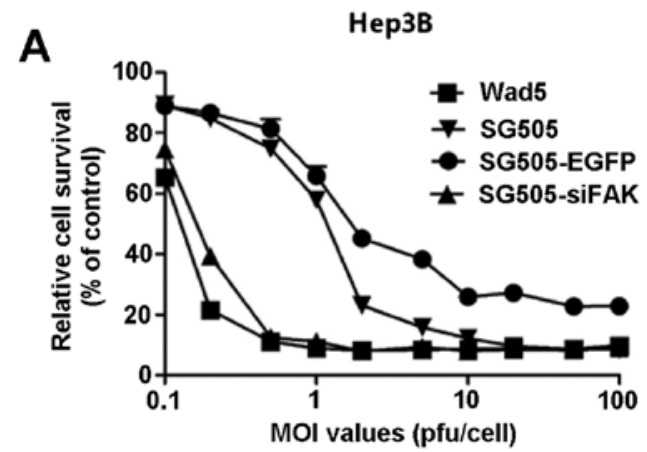

SMMC-7721
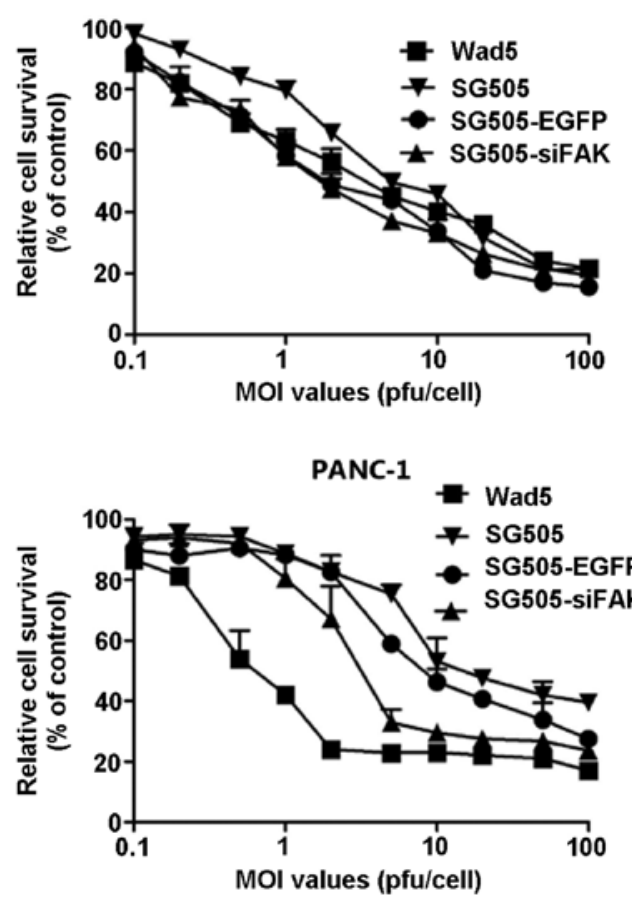

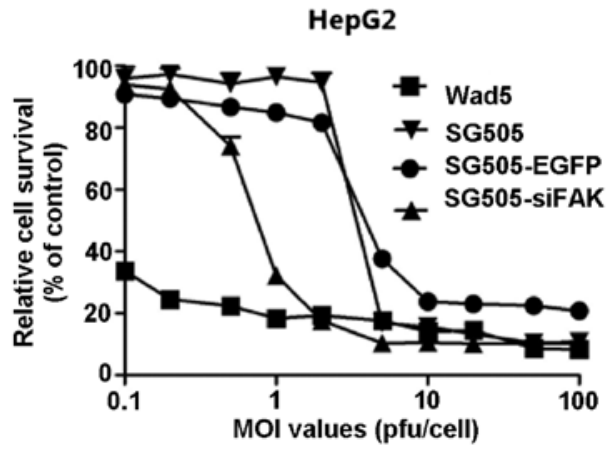

L02

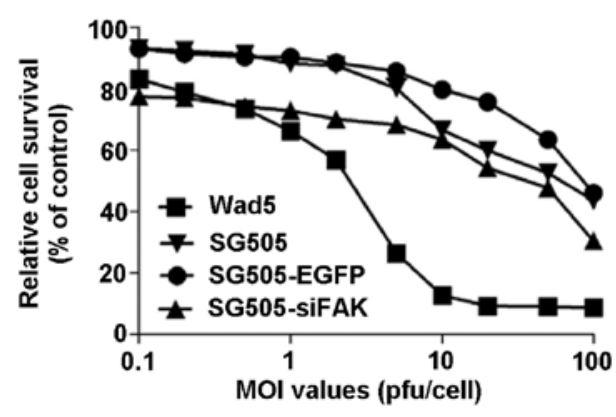

H460

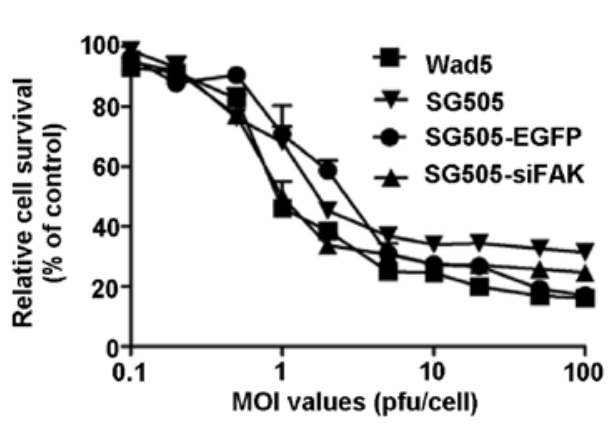

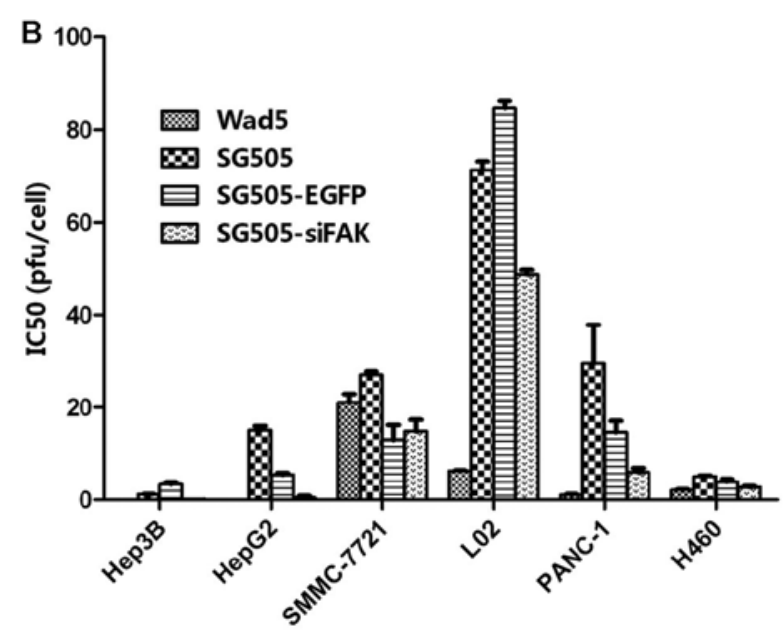

Figure 4. The antitumor effects of oncolytic adenoviruses in various cell lines. (A) SG505-siFAK had specific hepatoma-restricted anticancer effect in vitro. Cell viability of the Hep3B, HepG2, SMMC-7721 and L02 were assessed using the MTT assay in the presence of the therapeutic regimens as indicated. The cell viability of tumor cells and normal cells infected with increasing MOIs of various adenoviruses was assessed to recapitulate the clinical scenario. The inhibitory effects on the growth of HepG2, Hep3B, SMMC-7721, L02, PANC-1 and $\mathrm{H} 460$ cells increased continuously with the increasing virus tilter after 24 -h infection. (B) $\mathrm{IC}_{50}$ values that resulted in $50 \%$ of cell growth inhibition for Wad5, SG505, SG505-EGFP and SG505-siFAK in different cell types were calculated. Bars showed the mean and the error bars showed the standard error from at least three independent experiments.
MOI values in various cell lines. SG505-siFAK and Wad5 showed most evident cytotoxic effects in the Hep3B and HepG2 cell lines. To further study the cytotoxic effects of the viruses, we compared the $\mathrm{IC}_{50}$ values in the cell lines infected with Wad5, SG505, SG505-EGFP and SG505siFAK. The $\mathrm{IC}_{50}$ values of SG505-siFAK were $0.092 \pm 0.009$, $0.424 \pm 0.414,14.796 \pm 2.520,48.709 \pm 0.927,5.970 \pm 0.945$ and $2.710 \pm 0.244 \mathrm{pfu} / \mathrm{cell}$ in Hep3B, HepG2, SMMC-7721, L02, PANC-1 and $\mathrm{H} 460$, respectively. The $\mathrm{IC}_{50}$ values further confirmed that the SG505-siFAK showed strong cytotoxic effects to the AFP-positive tumor cell line, and was weakly cytotoxic in the pancreatic cancer line PANC-1 and large cell lung cancer cell line H460. Although Wad5 showed similar cytotoxic effects in Hep3B and $\mathrm{HepG} 2$ comparing to the SG505-siFAK, it had more potent cytotoxic effect to the normal liver cell L02 $(\mathrm{P}<0.01)$, therefore SG505-siFAK was mild to the normal liver cell comparing to Wad5.

Antitumor effect of dual-regulated oncolytic adenovirus in the nude mouse xenografts. To evaluate and compare the antitumor activity of the recombined oncolytic adenovirus in vivo, a liver cancer cell tumor xengraft model was established by inoculating AFP-positive Hep3B cells into the right back of 
A

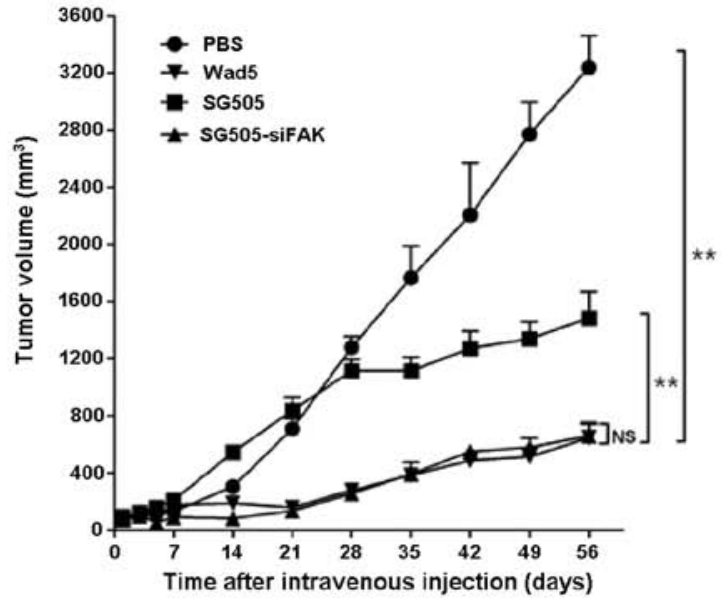

C

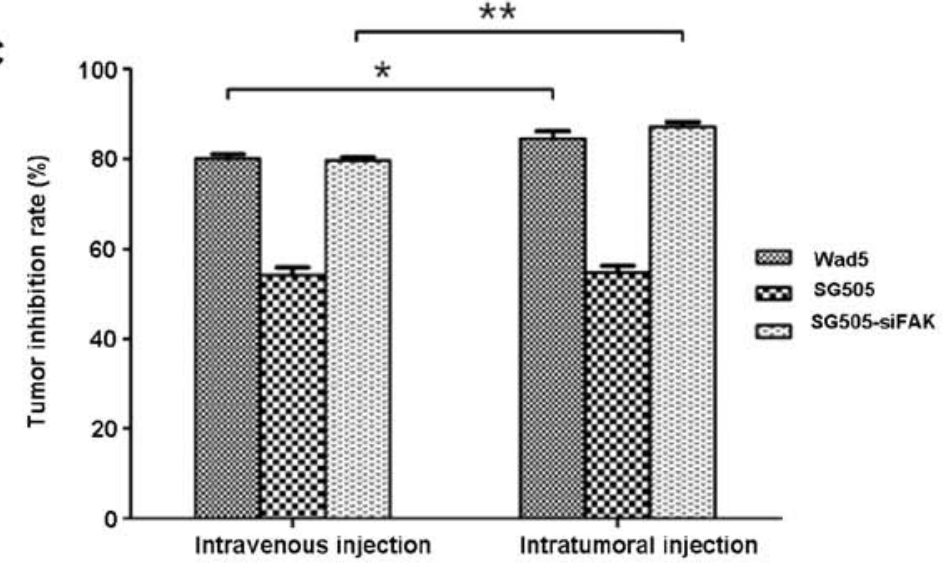

D
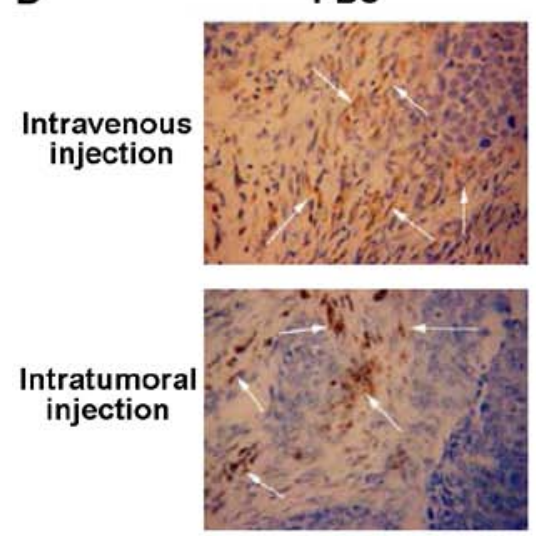

B

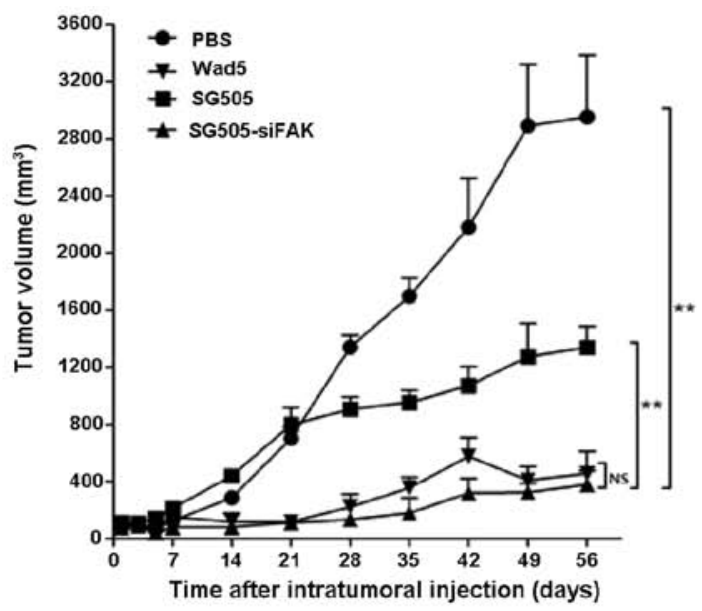

Wad5
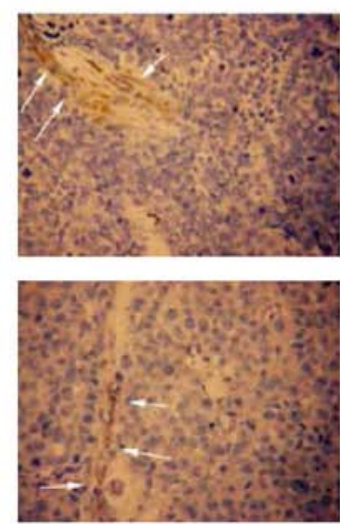

SG505
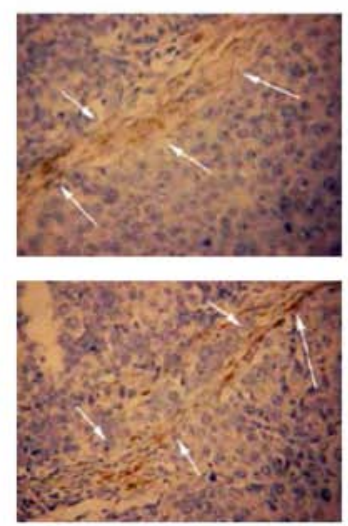

SG505-SIFAK
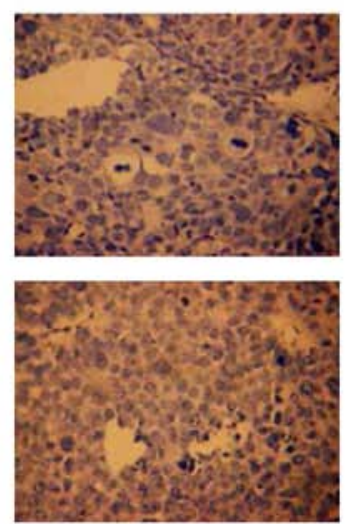

Figure 5. SG505-siFAK inhibited the growth of xeongraft tumors. (A) The tumor volumes of different groups treated with PBS, Wad5, SG505 and SG505-siFAK by intravenous or intratumoral injection. The tumor volumes treated intravenously with PBS, Wad5, SG505 and SG505-siFAK at day 56 were 3,237.5 $\pm 223.2,645.6 \pm 107.6,1,168.3 \pm 38.0$ and $659.2 \pm 82.4 \mathrm{~mm}^{3}$, respectively. The tumor volumes treated intratumorally with PBS, Wad5, SG505 and SG505-siFAK at day 56 were $2952.1 \pm 435.3,456.5 \pm 155.7,1339.2 \pm 147.6$ and $379.6 \pm 95.6 \mathrm{~mm}^{3}$. Tumor volumes were recorded as $\mathrm{mm}^{3} \pm \mathrm{SD}$, points indicated the mean value $(\mathrm{n}=10)$ and bars indicated $\mathrm{SD} ;{ }^{* *} \mathrm{P}<0.01$; ${ }^{*} \mathrm{P}<0.05$; NS, no significant difference. (C) Data collected 56 days after the initial virus treatment were analyzed to compare the tumor inhibition rates between the intravenous group and intratumoral injection. In the intravenous injection group, tumor inhibition rates of Wad5, SG505 and SG505-siFAK were 80.06, 54.14 and 79.63\%, respectively; in the intratumoral injection group, tumor inhibition rates of Wad5, SG505 and SG505-siFAK were 84.54, 56.64 and 87.14\%, respectively. (D) Representative micrographs of immonohistochemical staining for FAK in the groups. The specimens from various tumors injected with different adenoviruses were assayed by IHC and they revealed evidence of antitumor effects of SG505-siFAK in vivo. The FAK in cytoplasm of tumor cell was yellow or brown. FAK in the cells treated by the SG505-siFAK was stained negatively and FAK in the cells treated by the PBS, Wad5 and SG505 was stained positively, implying the successful gene knock-down by the shRNA. Arrow indicated cells that stained positively for FAK.

the nude mice. When the long diameter reached $5 \mathrm{~mm}$, PBS, SG505-EGFP and SG505-siFAK $\left(2 \times 10^{8} \mathrm{pfu} /\right.$ mice per time $)$ were administered to the mice by either intravenous injection or intratumoral injection in order to determine which kind of administration would cause more potent antitumor effect. Each nude mouse in the experimental group received a total of $1 \times 10^{9} \mathrm{pfu}$ of virus and all of the mice were sacrificed after 8 weeks. The volumes of tumors in the mice treated with PBS 
in both group grew rapidly and reached $\sim 1,300 \mathrm{~mm}^{3}$ within 4 weeks, suggesting the malignancy of the Hep3B in the study. SG505 and SG505-siFAK began to show remarkable inhibition effect by day 14 compared to the blank control group. Nude mice treated with SG505-siFAK at a total dosage of $1 \times 10^{9} \mathrm{pfu}$ per mouse showed similar antitumor ability when compared to the Wad5 in both groups $(\mathrm{P}>0.05)$ and stronger antitumor efficiency than SG505-EGFP in each group $(\mathrm{P}<0.01)$. It is worth noting that SG505-siFAK resulted in potent tumor growth inhibition without tumor regression, which resembled survival with tumor in the clinical scenario (Fig. 5A and B). The discrepancy of antitumor efficiency between two groups was accomplished by comparing the tumor inhibition rates, which demonstrated that SG505-siFAK and Wad5 had more robust antitumor capability in the intratumoral injection group than that in the intravenous injection (Fig. 5C). The main reason for the phenomenon was that the oncolytic adenovirus would be feasibly trapped and eliminated in the liver and the intratumoral injection could directly produce faster antitumor effects.

To confirm that the antitumor efficiency was mediated by the FAK siRNA engineered in the dual-regulated adenovirus, expression of FAK was assayed by immunohistochemistry in the tumor specimen when the mice were sacrificed. The FAK expression levels in the tumors treated with SG505-siFAK intratumorally or intravenously were markedly lower than those treated with PBS or SG505. Although SG505-siFAK and Wad5 showed similar antitumor capability, the FAK expression in the tumor tissue infected by the former was positive, and weakly positively infected by the latter (Fig. 5D). We thus deduced that SG505-siFAK might exert antitumor efficiency in vivo by combining the selective suppression effects of double-regulated oncolytic adenovirus to the liver cancer cells and the downregulation of FAK expression.

\section{Discussion}

In this study, we constructed double-regulated oncolytic adenovirus which proved to be a safe and efficient approach to suppress the development of AFP-positive liver cancer both in vitro and in vivo. Several promoters have been applied to achieve the selectivity for the tumor cells in the oncolytic systems, such as HRE, the prostate-specific antigen, osteocalcin, MUC1, midkine, Lplastin, E2F-1, UPII and Survivin genes (30-32). The promoters of these reconstructed oncolytic adenoviruses can be only activated in certain tumor cells which produced the special transcription factor and finally resulted in massive virus replication. We were inspired by the previous meaningful studies and decided to utilize the hTERT promoter to drive the E1A expression and hybrid HREAF promoter to drive the E1B expression, thus, SG505 was engineered based on the framework of Wad5 and the targeting therapeutic gene was introduced into the vector. The reason why AFP-promoter was chosen was that AFP is a widely-used clinical marker and it was feasible to choose suitable objects to receive the treatments. The recombined virus replication was potent in the AFP-positive liver cell lines (Hep3B and HepG2), exceeding that in the AFP-negative liver cell line (SMMC-7721), large cell lung cancer line (H460) and pancreatic cancer line (PANC-1) in spite of the enhanced HREAP promoter. Therefore, the recombined adenovirus showed specific infection capability in the AFP-positive liver cancer cells. SG505-siFAK was designed to selectively invade the AFP-positive liver cancer cell lines (Hep3B and HepG2) and produced more progeny viruses compared with the normal cell lines (BJ and L02). SG505-siFAK and SG505-EGFP derived from the SG505 shown similar selective replication (Fig. 2A). The western blotting also demonstrated the replication abilities of SG505, SG505-EGFP and SG505-siFAK were attenuated in the normal cells but were weaker than the wild adenovirus (Fig. 3). Thus, our data demonstrated the SG505 was a safe and efficient vector in the CTGVT.

The current strategy of CTGVT is to insert the targeting gene in the oncolytic adenovirus (33), therefore an appropriate antitumor gene is crucial for the success of CTGVT. FAK has been reported in the liver cancer tissue and proved to be a potential therapeutic target for $\mathrm{HCC}$. The present reports clarified that FAK was required for $\mathrm{c}-\mathrm{Met} / \beta$-catenin-driven hepatocarcinogenesis and activation of the FAK-Src signaling pathways contributes to HCC growth and metastasis, so gene knockdown of FAK provided a promising strategy to treat HCC $(34,35)$. Therefore, we decided to introduce a robust tool to knock down the FAK expression by RNA interference $(36,37)$. RNA interference has rapidly become a powerful tool for target validation and the most widely used gene-silencing technique in functional genomics due to its extremely high inhibitory activity and the fact that the inhibition is very specific (38). Our results demonstrated that a significant suppression of SG505-siFAK was achieved in AFP-positive Hep3B and HepG2 cell lines without causing too much damage to the normal liver cells (Fig. 4), which rendered the double-regulated oncolytic adenovirus remarkable safety. Regarding to the antitumor efficiency, The $\mathrm{IC}_{50}$ value of SG505 in Hep3B and HepG2 was 1.199 \pm 0.073 and $15.026 \pm 0.926 \mathrm{pfu} /$ cell, respectively, which was larger than that of SG505-siFAK $(\mathrm{P}<0.05)$. The results meant that the CTGVT therapy combined the benefits of virotherapy and gene therapy, producing comprehensive and synergetic effect (39).

We further confirmed the strong antitumor ability of SG505-siFAK in nude mouse xenograft model (Fig. 5). The SG505-siFAK induced more significant tumor regression than the SG505-EGFP in both intratumoral injection group and intravenous group. Besides, the SG505 was able to produce a considerable tumor growth inhibitory effect compared with the blank control group. It indicated that oncolytic adenovirus could cause tumor inhibition by itself and with the oncolytic adenovirus armed with antitumor gene. The potential side effects of the oncolytic adenovirus is hardly under the manipulation in nude mice because mice are known to be nonpermissive to the human adenovirus, therefore the antitumor efficiency discrepancy among the Wad5 and SG505-siFAK was not remarkable.

Although RNAi was more potent than other gene silencing methods, several inherent limitations in RNAi technology need to be overcame before carrying out clinical trials, including transfection, incomplete silencing of tumor cells, low specificity, immunological reactions, undesired gene insertions (40). Above all, the RNA interference technology only knocked down gene expression but generally didn't eliminate it (41). 
Consistent with the previous studies, our data also indicated that the tumors were not eradicated totally (Fig. 5) (42). To accomplish the total tumor inhibition, we postulated that two therapeutic genes could be used in the dual-regulated adenovious vector, which will completely eliminate the hepatoma xenograft (39). The liver cancer suppressor gene included tumor necrosis factor-related apoptosis inducing ligand (TRAIL), hepatocellular carcinoma suppressor 1 (HCCS1), and suppressor of cytokine signaling 3 (SOCS3) (43-45). The previous studies on the HCC and colorectal tumor xenografts have proved the viability and feasibility (7). Besides, the CTGVT could also be combined with chemotherapeutic drugs, thus reducing the side effects and drug resistance (46).

In conclusion, the present data demonstrated that SG505-siFAK, a novel recombined dual-regulated oncolytic adenovirus, could infect and kill liver cancer cells specifically and effectively. In addition, our study provided evidence that siRNA directly delivered against FAK by the SG505 possessed the ability to downregulate the targeting gene and suppressed the progression of human liver cancer cells in the xenografts in the mouse model. Hence, the CTGVT approach provides a promising method for the effective treatment of HCC and more studies are needed to verify its potential therapeutic effects in clinical trials.

\section{Acknowledgements}

This study was supported by the National Natural Science Foundation of China, no. 30872512.

\section{References}

1. Jemal A, Bray F, Center MM, Ferlay J, Ward E and Forman D: Global cancer statistics. CA Cancer J Clin 61: 69-90, 2011.

2. Tabrizian P, Roayaie S and Schwartz ME: Current management of hepatocellular carcinoma. World J Gastroenterol 20 : 10223-10237, 2014.

3. Llovet JM, Fuster J and Bruix J: Intention-to-treat analysis of surgical treatment for early hepatocellular carcinoma: Resection versus transplantation. Hepatology 30: 1434-1440, 1999.

4. Bai W, Wang YJ, Zhao Y, Qi XS, Yin ZX, He CY, Li RJ, Wu KC, Xia JL, Fan DM, et al: Sorafenib in combination with transarterial chemoembolization improves the survival of patients with unresectable hepatocellular carcinoma: A propensity score matching study. J Dig Dis 14: 181-190, 2013.

5. Graf D, Vallböhmer D, Knoefel WT, Kröpil P, Antoch G, Sagir A and Häussinger D: Multimodal treatment of hepatocellular carcinoma. Eur J Intern Med 25: 430-437, 2014.

6. Russell SJ, Peng KW and Bell JC: Oncolytic virotherapy. Nat Biotechnol 30: 658-670, 2012.

7. Cao X, Yang M, Wei RC, Zeng Y, Gu JF, Huang WD, Yang DQ, Li HL, Ding M, Wei N, et al: Cancer targeting gene-viro-therapy of liver carcinoma by dual-regulated oncolytic adenovirus armed with TRAIL gene. Gene Ther 18: 765-777, 2011.

8. Wei RC, Cao X, Gui JH,Zhou XM,Zhong D, Yan QL, Huang WD, Qian QJ, Zhao FL and Liu XY: Augmenting the antitumor effect of TRAIL by SOCS3 with double-regulated replicating oncolytic adenovirus in hepatocellular carcinoma. Hum Gene Ther 22 1109-1119, 2011.

9. Hu ZB, Wu CT, Wang H, Zhang QW, Wang L, Wang RL, Lu ZZ and Wang LS: A simplified system for generating oncolytic adenovirus vector carrying one or two transgenes. Cancer Gene Ther 15: 173-182, 2008.

10. Kasala D, Choi JW, Kim SW and Yun CO: Utilizing adenovirus vectors for gene delivery in cancer. Expert Opin Drug Deliv 11: 379-392, 2014

11. Liu XY, Gu JF and Shi WF: Targeting gene-virotherapy for cancer. Acta Biochim Biophys Sin 37: 581-587, 2005.
12. Huang $\mathrm{Q}$, Zhang $\mathrm{X}$, Wang $\mathrm{H}$, et al: A novel conditionally replicative adenovirus vector targeting telomerase-positive tumor cells. Clin Cancer Res 10: 1439-1445, 2004.

13. Hahn WC: Targeting cancer with telomerase: commentary re Q Huang et al., a novel conditionally replicative adenovirus vector targeting telomerase-positive tumor cells. Clin. Cancer Res., 10: 1439-1445, 2004. Clin Cancer Res 10: 1203-1205, 2004.

14. Tangkijvanich $\mathrm{P}$, Anukulkarnkusol N, Suwangool $\mathrm{P}$ Lertmaharit $\mathrm{S}$, Hanvivatvong $\mathrm{O}$, Kullavanijaya $\mathrm{P}$ and Poovorawan Y: Clinical characteristics and prognosis of hepatocellular carcinoma: Analysis based on serum alpha-fetoprotein levels. J Clin Gastroenterol 31: 302-308, 2000.

15. Li Y, Yu DC, Chen Y, Amin P, Zhang H, Nguyen N and Henderson DR: A hepatocellular carcinoma-specific adenovirus variant, CV890, eliminates distant human liver tumors in combination with doxorubicin. Cancer Res 61: 6428-6436, 2001.

16. Ido A, Uto H, Moriuchi A, Nagata K, Onaga Y, Onaga M, Hori T, Hirono S, Hayashi K, Tamaoki T, et al: Gene therapy targeting for hepatocellular carcinoma: Selective and enhanced suicide gene expression regulated by a hypoxia-inducible enhancer linked to a human alpha-fetoprotein promoter. Cancer Res 61: 3016-3021, 2001.

17. Kwon OJ, Kim PH, Huyn S, Wu L, Kim M and Yun CO: A hypoxia- and \{alpha\}-fetoprotein-dependent oncolytic adenovirus exhibits specific killing of hepatocellular carcinomas. Clin Cancer Res 16: 6071-6082, 2010.

18. Huang TG, Savontaus MJ, Shinozaki K, Sauter BV and Woo SL: Telomerase-dependent oncolytic adenovirus for cancer treatment. Gene Ther 10: 1241-1247, 2003.

19. Yuan Z, Zheng Q, Fan J, Ai KX, Chen J and Huang XY: Expression and prognostic significance of focal adhesion kinase in hepatocellular carcinoma. J Cancer Res Clin Oncol 136: 1489-1496, 2010.

20. Fujii T, Koshikawa K, Nomoto S, Okochi O, Kaneko T, Inoue S, Yatabe Y, Takeda S and Nakao A: Focal adhesion kinase is overexpressed in hepatocellular carcinoma and can be served as an independent prognostic factor. J Hepatol 41: 104-111, 2004.

21. Golubovskaya VM: Focal adhesion kinase as a cancer therapy target. Anticancer Agents Med Chem 10: 735-741, 2010.

22. He D, Sun L, Li C, Hu N, Sheng Y, Chen Z, Li X, Chi B and Jin N: Anti-tumor effects of an oncolytic adenovirus expressing hemagglutinin-neuraminidase of Newcastle disease virus in vitro and in vivo. Viruses 6: 856-874, 2014.

23. Boncler M, Różalski M, Krajewska U, Podsędek A and Watala C: Comparison of PrestoBlue and MTT assays of cellular viability in the assessment of anti-proliferative effects of plant extracts on human endothelial cells. J Pharmacol Toxicol Methods 69: 9-16, 2014.

24. Ford AL, An H, Kong L, Zhu H, Vo KD, Powers WJ, Lin W and Lee JM: Clinically relevant reperfusion in acute ischemic stroke: MTT performs better than Tmax and TTP. Transl Stroke Res 5: 415-421, 2014.

25. Liu L, Wu W, Zhu G, Liu L, Guan G, Li X, Jin N and Chi B: Therapeutic efficacy of an hTERT promoter-driven oncolytic adenovirus that expresses apoptin in gastric carcinoma. Int J Mol Med 30: 747-754, 2012.

26. Itoh S, Maeda T, Shimada M, Aishima S, Shirabe K, Tanaka S and Maehara Y: Role of expression of focal adhesion kinase in progression of hepatocellular carcinoma. Clin Cancer Res 10: 2812-2817, 2004.

27. Yu DC, Chen Y, Seng M, Dilley J and Henderson DR: The addition of adenovirus type 5 region E3 enables calydon virus 787 to eliminate distant prostate tumor xenografts. Cancer Res 59: 4200-4203, 1999.

28. Nettelbeck DM, Rivera AA, Balagué C, Alemany R and Curiel DT: Novel oncolytic adenoviruses targeted to melanoma: Specific viral replication and cytolysis by expression of E1A mutants from the tyrosinase enhancer/promoter. Cancer Res 62: 4663-4670, 2002.

29. Leitner S, Sweeney K, Oberg D, Davies D, Miranda E, Lemoine NR and Halldén G: Oncolytic adenoviral mutants with E1B19K gene deletions enhance gemcitabine-induced apoptosis in pancreatic carcinoma cells and anti-tumor efficacy in vivo. Clin Cancer Res 15: 1730-1740, 2009.

30. Dong X, Qu W, Ma S, Zhu Z, Zheng C, He A, Karlsson A, Xu K and Zheng X: Potent antitumoral effects of targeted promoterdriven oncolytic adenovirus armed with Dm-dNK for breast cancer in vitro and in vivo. Cancer Lett 328: 95-103, 2013. 
31. Wang L, Zhang Y, Zhao J, Xiao E, Lu J, Fu S and Wang Z: Combination of bladder cancer-specific oncolytic adenovirus gene therapy with cisplatin on bladder cancer in vitro. Tumour Biol 35: 10879-10890, 2014.

32. Liu XR, Cai Y, Cao X, Wei RC, Li HL, Zhou XM, Zhang KJ, Wu S, Qian QJ, Cheng B, et al: A new oncolytic adenoviral vector carrying dual tumour suppressor genes shows potent anti-tumour effect. J Cell Mol Med 16: 1298-1309, 2012.

33. He B,Huang X, Liu X and Xu B: Cancer targeting gene-viro-therapy for pancreatic cancer using oncolytic adenovirus ZD55-IL-24 in immune-competent mice. Mol Biol Rep 40: 5397-5405, 2013.

34. Shang N, Arteaga M,Zaidi A, Stauffer J, Cotler SJ,Zeleznik-Le NJ, Zhang J and Qiu W: FAK is required for c-Met/beta-catenindriven hepatocarcinogenesis. Hepatology 61: 214-226 2014.

35. Dai Z, Zhou SL, Zhou ZJ, Bai DS, Xu XY, Fu XT, Chen Q, Zhao YM, Zhu K, Yu L, et al: Capn4 contributes to tumour growth and metastasis of hepatocellular carcinoma by activation of the FAK-Src signalling pathways. J Pathol 234: 316-328, 2014.

36. Ko BS, Jan YJ, Chang TC, Liang SM, Chen SC, Liu TA, Wu YM, Wang $\mathbf{J}$ and Liou JY: Upregulation of focal adhesion kinase by $14-3-3 \varepsilon$ via $\mathrm{NF} \kappa \mathrm{B}$ activation in hepatocellular carcinoma Anticancer Agents Med Chem 13: 555-562, 2013.

37. Cai L, Han J, Zhuo X, Xiong Y, Dong J and Li X: Overexpression and significance of focal adhesion kinase in hepatocellula carcinoma and its relationship with HBV infection. Med Oncol 26: 409-414, 2009.

38. Takeshita F and Ochiya T: Therapeutic potential of RNA interference against cancer. Cancer Sci 97: 689-696, 2006.
39. Liu XY: Targeting gene-virotherapy of cancer and its prosperity. Cell Res 16: 879-886, 2006.

40. Grünweller A, Wyszko E, Bieber B, Jahnel R, Erdmann VA and Kurreck J: Comparison of different antisense strategies in mammalian cells using locked nucleic acids, 2'-O-methyl RNA, phosphorothioates and small interfering RNA. Nucleic Acids Res 31: 3185-3193, 2003.

41. Prados J, Melguizo C, Roldan H, Alvarez PJ, Ortiz R, Arias JL and Aranega A: RNA interference in the treatment of colon cancer. BioDrugs 27: 317-327, 2013.

42. Liu W, Zhu F, Jiang Y, Sun D, Yang B and Yan H: siRNA targeting survivin inhibits the growth and enhances the chemosensitivity of hepatocellular carcinoma cells. Oncol Rep 29: 1183-1188, 2013.

43. Pei Z, Chu L, Zou W, Zhang Z, Qiu S, Qi R, Gu J, Qian C and Liu X: An oncolytic adenoviral vector of Smac increases antitumor activity of TRAIL against HCC in human cells and in mice. Hepatology 39: 1371-1381, 2004.

44. Zhang J, Gan Y, Gu J, Hu J, Liu X and Zhao X: Potent anti-hepatoma efficacy of HCCS1 via dual tumor-targeting genevirotherapy strategy. Oncol Rep 20: 1035-1040, 2008.

45. Wu WY, Kim H, Zhang CL, Meng XL and Wu ZS: Loss of suppressors of cytokine signaling 3 promotes aggressiveness in hepatocellular carcinoma. J Invest Surg 27: 197-204, 2014.

46. Guo X, Wang W, Zhou F, Lu Z, Fang R, Jia F, Bu X, Li R, Zhang B, Wu M, et al: siRNA-mediated inhibition of hTERT enhances chemosensitivity of hepatocellular carcinoma. Cancer Biol Ther 7: 1555-1560, 2008. 